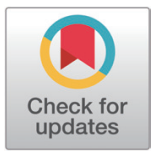

Received: Feb 2, 2021

Revised: Apr 19, 2021

Accepted: Apr 21, 2021

\#These authors contributed equally to this work.

${ }^{*}$ Corresponding author Hyeun Bum Kim

Department of Animal Resource and

Science, Dankook University, Cheonan 31116, Korea.

Tel: +82-41-550-3653

E-mail: hbkim@dankook.ac.kr

Jin Ho Cho

Division of Food and Animal Science, Chungbuk National University,

Cheongju 28644, Korea.

Tel: +82-43-261-2544

E-mail: jinhcho@chungbuk.ac.kr

Copyright ( 2021 Korean Society of Animal Sciences and Technology. This is an Open Access article distributed under the terms of the Creative Commons Attribution Non-Commercial License (http:// creativecommons.org/licenses/bync/4.0/) which permits unrestricted non-commercial use, distribution, and reproduction in any medium, provided the original work is properly cited.

ORCID

Yong Ju Kim

https://orcid.org/0000-0002-0960-0884

\section{Evaluation of pig behavior changes related to temperature, relative humidity, volatile organic compounds, and illuminance}

\author{
Yong Ju Kim ${ }^{1 \#}$, Min Ho Song ${ }^{2 \#}$, Sang In Lee ${ }^{3 \#}$, Ji Hwan Lee ${ }^{1}$, Han Jin Oh', \\ Jae Woo An ${ }^{1}$, Se Yeon Chang ${ }^{1}$, Young Bin Go ${ }^{1}$, Beom Jun Park', \\ Min Seok Jo ${ }^{1}$, Chang Gyu Lee ${ }^{4}$, Hyeun Bum Kim ${ }^{5 *}$ and Jin Ho Cho ${ }^{1 *}$ \\ ${ }^{1}$ Division of Food and Animal Science, Chungbuk National University, Cheongju 28644, Korea \\ ${ }^{2}$ Department of Animal Science and Biotechnology, Chungnam National University, Daejeon 34134, \\ Korea \\ ${ }^{3}$ Department of Animal Biotechnology, Kyungpook National University, Sangju 37224, Korea \\ ${ }^{4}$ Dronic, Daejeon 35240, Korea \\ ${ }^{5}$ Department of Animal Resource and Science, Dankook University, Cheonan 31116, Korea
}

\section{Abstract}

The objective of this study was evaluation of pig behavior changes related to temperature, relative humidity, volatile organic compounds (VOCs), and illuminance. A total of 24 growing pigs ([Yorkshire $\times$ Landrace] $\times$ Duroc) were used in the experiment. A sensor was installed at a height of $0.5 \mathrm{~m}$ in the center of the pig house. In experiment 1 , temperature was changed every four days to $18^{\circ} \mathrm{C}(\mathrm{T} 1), 22^{\circ} \mathrm{C}(\mathrm{T} 2), 26^{\circ} \mathrm{C}(\mathrm{T} 3)$, and then $30^{\circ} \mathrm{C}(\mathrm{T} 4)$. In experiment 2 , relative humidity was adjusted to $45 \%$ (low humidity $[\mathrm{LH}]$ ), $60 \%$ (middle humidity [MH]), and then $75 \%$ (high humidity $[\mathrm{HH}]$ ) for four days. In experiment 3 , after cleaning the pig house just before experiment, only minimal ventilation was provided. VOCs and pig behaviors were observed for 7 days without cleaning the pig house. In experiment 4, three light bulbs of 40 W (470 lumens / 45 Ix; low illuminance [LI]), 75 W (1,055 lumens / 103 Ix; middle illuminance $[\mathrm{MI}])$, and $100 \mathrm{~W}$ (1,521 lumens / $146 \mathrm{~lx}$; high illuminance [HI]) were used for four days each. Pig behavior analysis was performed for following criteria : Feed intake, Standing, Lying, Sitting, Drink water, Rooting, Posture transition (lying-standing), Posture transition (standing-lying), Wallowing, and Biting. In experiment 1 , feed intake time was lower $(p<0.05)$ for the T3 than other treatment groups. Standing time was highest $(p<0.05)$ for the T1 and lowest $(p$ $<0.05)$ for the T3. Lying time was shorter $(p<0.05)$ in T1 and T2 compared to T3 and T4. Drinking frequency was higher $(p<0.05)$ for the T4 than other treatment groups. In experiment 2 , the frequency of rooting and wallowing increased $(p<0.05)$ with increasing humidity. LH showed the lowest $(p<0.05)$ rooting frequency and HH showed the highest $(p<0.05)$ rooting frequency. In experiment 3 , VOCs concentration did not $(p>0.05)$ change pig behavior. In experiment 4 , lying time was the longest $(p<0.05)$ at $\mathrm{LI}$ and shortest $(p<0.05)$ at $\mathrm{HI}$. Therefore, pig behavior is heavily influenced by the environment, especially temperature and humidity. However, correlation between pig behavior to VOCs and illuminance seems to be needed more research.

Keywords: Pig behavior, Temperature, Relative humidity, Volatile organic compounds, Illuminance 
Min Ho Song

https://orcid.org/0000-0002-4515-5212

Sang In Lee

https://orcid.org/0000-0002-0019-1834

Ji Hwan Lee

https://orcid.org/0000-0001-8161-4853

Han Jin Oh

https://orcid.org/0000-0002-3396-483X

Jae Woo An

https://orcid.org/0000-0002-5602-5499

Se Yeon Chang

https://orcid.org/0000-0002-5238-2982

Young Bin Go

https://orcid.org/0000-0002-5351-6970

Beom Jun Park

https://orcid.org/0000-0001-6741-4716

Min Seok Jo

https://orcid.org/0000-0001-6742-4316

Chang Gyu Lee

https://orcid.org/0000-0002-7689-0148

Hyeun Bum Kim

https://orcid.org/0000-0003-1366-6090

Jin Ho Cho

https://orcid.org/0000-0001-7151-0778

\section{Competing interests}

No potential conflict of interest relevant to

this article was reported.

Funding sources

This research was supported by Chungbuk

National University Korea National University

Development Project (2020).

Acknowledgements

Not applicable.

\section{Availability of data and material}

Upon reasonable request, the datasets

of this study can be available from the

corresponding author.

Authors' contributions

Conceptualization: Kim YJ, Song MH, Lee

SI, Lee JH.

Data curation: Kim YJ, Lee SI.

Formal analysis: Kim YJ, Lee SI, Park BJ, Jo MS.

Investigation: Lee JH, Oh HJ, An JW, Chang

SY, Go YB, Lee CG.

Writing - original draft: Kim YJ, Song MH.

Writing - review \& editing: Song MH, Kim HB, Cho JH.

Ethics approval and consent to participate The experimental protocol was approved and conducted under the guidelines of the Animal Care and Use Committee of Chungbuk National University (CBNUA-1445-20-01).

\section{INTRODUCTION}

The pig industry has expanded rapidly over the last century. The number of pigs one person can manage is limited, and the number of pigs per farm is steadily increasing. Information and Communication Technology (ICT) is an indispensable element in matters such as growth performance, feed efficiency, breeding environment, disease, reproduction, and risk factors through limited human resources in the swine field. In the case of Korea, the introduction of ICT began in recent years [1]. The ICT technology is being applied in Korea to basic fields, for example, changes in temperature and humidity, fire detection in farms, and as real-time monitoring systems for feed bins in pig farms. However, the diversity and applications of ICT are limited compared to those in foreign countries.

In particular, studies on the environment (temperature, humidity, volatile organic compounds [VOCs], and illuminance) in the pig house and the corresponding pig behavior model are insufficient, and scientific research on pig house monitoring is required. In addition, there is a desperate need for research that can finally evaluate the reactivity of conductors by applying an ICT-based integrated control system based on the dynamics of reliable internal environmental variables in the pig house to properly utilize the sensing base construction information. Most farms using ICT in Korea have installed and operated environmental sensors, closed-circuit televisions (CCTVs), and specification management devices, but the technology to use the data obtained from these devices is lacking. Recently, technology was developed in the United States to measure the status of pigs in real-time by combining video analysis technology with images obtained in real-time. The digitization process that incorporate systems, software, devices, standard operating procedures, analytics, and communications is developing in the swine sector and will upgrade production efficiency, health, and welfare on farms under the quality standards that modern production requires [2]. Even now, in smart farming systems, farmers can monitor and management remotely, on the basis of real-time digital information instead direct observation and manual tasks on-site [3].

Therefore, the purpose of this experiment was to evaluate the behavioral changes in pigs according to temperature, humidity, VOCs, and illuminance inside the pig house.

\section{MATERIALS AND METHODS}

The experimental protocol for the four experiments was approved (CBNUA-1445-20-01) by the Institutional Animal Care and Use Committee of Chungbuk National University, Cheongju, Korea.

\section{Animals and housing}

A total of 24 growing pigs ([Yorkshire $\times$ Landrace] $\times$ Duroc) were used in the experimental period between April 2020 and May 2020 at the Chungbuk National University farm. The room space was $96 \mathrm{~m}^{2}$ and consisted of six pens, with four pigs per pen. All experiments were conducted in the same room. A sensor (IOT Sensor Monitoring Emailer, WIZ BASE, Seoul, Korea) was installed at a height of $0.5 \mathrm{~m}$ in the center of the pig house to measure temperature, relative humidity, and VOCs every 10 minutes. All pigs were fed a corn-soybean meal-based diet that satisfied the nutrient requirements recommended by the National Research Council [4] and had free access to water and feed.

\section{Experimental design and management}

In experiment 1, the temperature of the room was arbitrarily adjusted to examine the changes in pig behavior according to temperature. The experiment was conducted over 16 days, and the 
temperature was changed every four days to $18^{\circ} \mathrm{C}(\mathrm{T} 1), 22^{\circ} \mathrm{C}(\mathrm{T} 2), 26^{\circ} \mathrm{C}(\mathrm{T} 3)$, and then $30^{\circ} \mathrm{C}(\mathrm{T} 4)$. After the temperature change, an adaptation period of three days was provided, the behavioral changes was observed for $24 \mathrm{~h}$. The temperature was set using a heating device inside the pig house. Other environmental conditions except temperature remained constant (relative humidity, 50\%; VOCs, 42ppb; 470 lumens [45 lx]).

In experiment 2 , the relative humidity of the room was arbitrarily adjusted to observe changes in the behavior of pigs according to the relative humidity. The experiment was conducted over 12 days, and a humidifier (SGM-L124, Geek Aire, Beijing, China) was installed in the pig house to adjust the humidity. The relative humidity was adjusted to 45\% (low humidity [LH]), $60 \%$ (middle humidity $[\mathrm{MH}]$ ), and then $75 \%$ (high humidity $[\mathrm{HH}]$ ) for four days. After the humidity change, an adaptation period of three days was provided, and the behavioral changes observed for $24 \mathrm{~h}$. Other environmental conditions except humidity remained constant (temperature, $22^{\circ} \mathrm{C}$; VOCs, 43ppb; 470 lumens [ $45 \mathrm{~lx}])$.

In experiment 3 , the concentration of VOCs was gradually increased to determine the behavioral changes of pigs according to VOCs in the pig house. The experiment was conducted for a total of seven days, and after cleaning the pig house just before the start of the experiment, $15 \mathrm{~kg}$ of sawdust was placed on the floor of each pen. After that, only minimal ventilation was provided, and pig behavior was observed for seven days without cleaning the pig houses. Other environmental conditions remained constant (temperature, $22^{\circ} \mathrm{C}$; relative humidity, 50\%; 470 lumens [ $\left.45 \mathrm{~lx}\right]$ ).

In experiment 4, the illuminance of the room was arbitrarily adjusted to observe changes in the behavior of pigs according to illuminance. The experiment was conducted for a total of 12 days. Total of 12 incandescent bulbs (EZenlight, Daegu, Korea) were installed on the ceiling of a $96 \mathrm{~m}^{2}$ pig house, and three light bulbs of $40 \mathrm{~W}$ (470 lumens / $45 \mathrm{~lx}$; low illuminance [LI]), $75 \mathrm{~W}$ (1,055 lumens / 103 lx; middle illuminance), and $100 \mathrm{~W}$ (1,521 lumens / 146 lx; high illuminance [HI]) were used for four days each. The lights were arranged to generate an even distribution of illumination across all sections. After the illuminance change, an adaptation period of three days was provided, and the behavioral changes was observed for $24 \mathrm{~h}$. Other environmental conditions remained constant (temperature, $22^{\circ} \mathrm{C}$; relative humidity, $50 \%$; VOCs, $42 \mathrm{ppb}$ ).

\section{Analysis}

\section{Pig behavior}

Image data collection for each pig was recorded using six day/night infrared cameras (QNB$7080 \mathrm{RH}$, Hanwha, Seoul, Korea) installed $3 \mathrm{~m}$ above each pen. Two pigs were randomly selected per pen, and a total of 12 pigs were behaviorally analyzed. The observer collected data based on research of Yang et al. [5] and one observer performed all observations and video analysis to ensure consistent results. Pig behavior analysis was performed for the following criteria (Fig. 1): A, Feed intake: the act of eating with the head in a feed bin, or similar behavior; B, Standing: the act of standing still without any other action, with the forelimbs and hind legs stretched perpendicularly to the floor or similar behavior; C, Lying: the act of lying in the most comfortable position with the head, front legs, back legs, and abdomen touching the floor or similar behavior; D, Sitting: two front legs straight to the floor, two rear legs and hips sitting in contact with the floor or similar behavior; E, Drink water: the act of drinking water for about 10 seconds by putting the mouth to a drinking nipple where water comes out or similar behavior; F, Rooting: the act of repeatedly scratching the floor using the nose and forelegs as if there was something on the floor or to relieve itching or similar behavior; G, Posture transition (lying-standing): the act of changing from lying down to standing up, an act that occurs when the two front legs are extended first, and the back legs are naturally extended; $\mathrm{H}$, Posture transition (standing-lying): the act of changing from standing up 
A

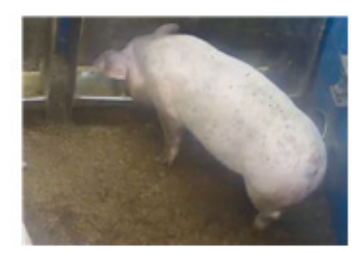

F

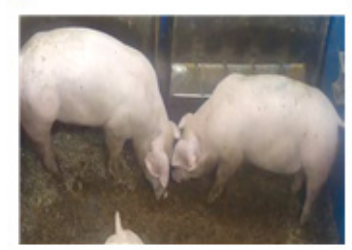

B

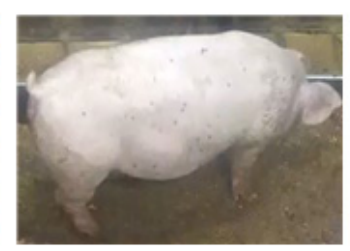

G

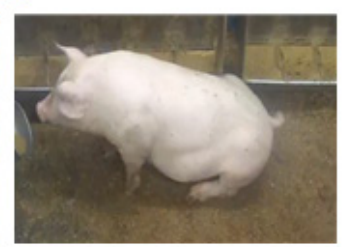

$\mathrm{C}$

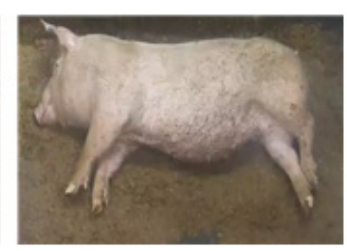

H

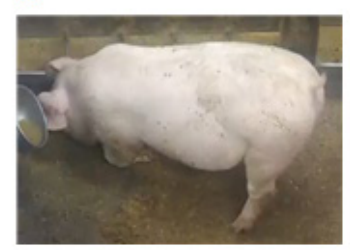

D

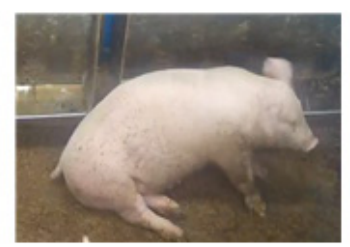

I

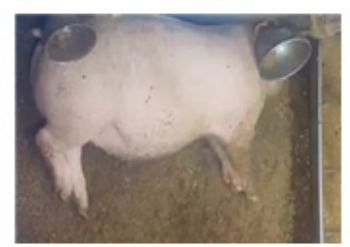

$\mathrm{E}$

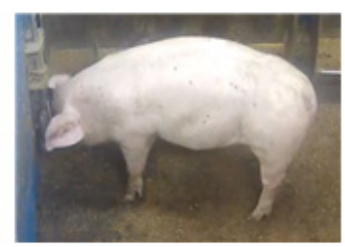

J

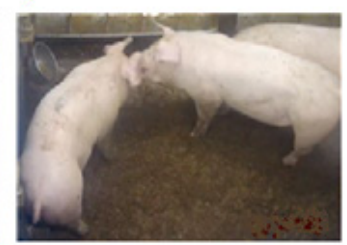

Fig. 1. Classification of pig behavior changes. (A) Feed intake, (B) Standing, (C) Lying, (D) Sitting, (E) Drink water, (F) Rooting, (G) Posture transition (lyingstanding), (H) Posture transition (standing-lying), (I) Wallowing, (J) Biting.

to lying down, the act of bending the two front legs to the floor first, and then lying down naturally with the two back legs folded; I, Wallowing: the act of laying with the back on sawdust, puddles or feces, and rolling around; J, Biting: the act of biting another pig's ear, mouth, or tail with its teeth, and then biting it again or similar behavior.

\section{Temperature and relative humidity}

Air temperature and relative humidity were measured at the center of the pig house by thermometers linked to a computer-based data-logging system. The thermometer was calibrated in the air prior to testing so the temperature calculations and relative humidity were considered precise to within $\pm 0.1^{\circ} \mathrm{C}$ and $\pm 1.5 \%$, respectively. During the experimental period, the data-logger automatically recorded temperature and relative humidity every 10 minutes.

\section{Volatile organic compounds}

VOCs in the pig house were measured using a photoionization detector (PID) attached to the sensor. The PID was calculated by intaking gas from the target of the measurement and releasing ultraviolet light into the measured gas to obtain the detection current proportional to the concentration of the VOCs by ionizing it according to the physical properties of the gas and collecting the ion into the electrodes. The types of VOCs measured were gases with an ionization potential that was less than the energy of ultraviolet rays, such as benzene, toluene, xylene, ethylbenzene, methylethylketone, acetaldehyde, trichloroethylene, tetrachloroethylene, mercaptan, and diethylamine.

\section{Illuminance}

The illuminance intensity was measured using an illuminometer (TES-1330A, TES, Taipei, Taiwan) at a certain time every day for the 12 days of the experiment. Measurements were taken at the pig's eye-height and oriented horizontally with the detector facing upward in the center of the section, with the prior establishment that no light spilled from the adjoining segment. The light was measured using the multi-point method approved by the Korea Industrial Standards Association (Fig. 2) [6].

$$
\mathrm{E}=1 \mathrm{i} \Sigma \mathrm{Emi} \quad \text { (Eq. 1) [6] }
$$




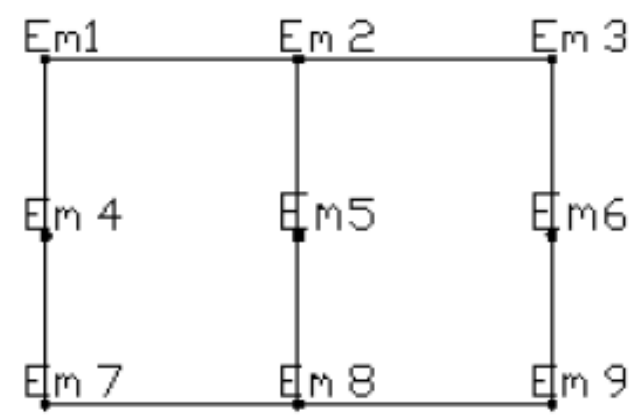

Fig. 2. Location of illuminance measurement by the multiple-point method of the Korean Standards [6].

\section{Statistical analysis}

The correlation of pig behavior indices and environmental factors was statistically analyzed by the generalized linear model using IBM SPSS statistics v.25 (SPSS, Chicago, IL, USA). The difference between the treatment groups was determined using Tukey's honest significance difference test with a significant $p$-value of less than 0.05 .

\section{RESULTS AND DISCUSSION}

The effects of temperature on pig behavior changes of experiment 1 are shown in Table 1. Feed intake time was lower $(p<0.05)$ for the T3 than other treatment groups. Standing time was the longest $(p<0.05)$ in T1 and the shortest in T4, but there was no significant difference $(p$ $>0.05)$ between T4 and T3. Lying time was shorter $(p<0.05)$ in T1 and T2 compared to T3 and T4, and there was no significant difference between T1 and T2, and T3 and T4. Drinking frequency increased $(p<0.05)$ as the temperature increased and was significantly higher $(p<0.05)$ in T4. As the temperature increased, the number of wallowing and biting events also increased. Other behaviors were not affected $(p>0.05)$ by temperature changes. In this experiment, high

Table 1. Effects of temperature on pig behavior

\begin{tabular}{|c|c|c|c|c|c|c|}
\hline Items & T1 & T2 & T3 & T4 & SE & $p$-value \\
\hline \multicolumn{7}{|l|}{ Basic behavior (min/hour) } \\
\hline Feed intake & $5.32^{\mathrm{a}}$ & $5.26^{\mathrm{ab}}$ & $4.98^{b}$ & $4.17^{\mathrm{C}}$ & 0.02 & 0.003 \\
\hline Lying & $43.86^{b}$ & $43.91^{\mathrm{b}}$ & $45.16^{a}$ & $45.84^{\mathrm{a}}$ & 0.03 & 0.039 \\
\hline Sitting & 2.75 & 2.68 & 2.97 & 3.02 & 0.01 & 0.115 \\
\hline Rooting & 0.97 & 1.05 & 1.12 & 1.38 & 0.01 & 0.068 \\
\hline Posture transition (lying-standing) & 3.56 & 3.49 & 3.12 & 3.87 & 0.03 & 0.566 \\
\hline Posture transition (standing-lying) & 3.59 & 3.43 & 3.17 & 3.81 & 0.02 & 0.491 \\
\hline Wallowing & $5.13^{\mathrm{c}}$ & $5.71^{\mathrm{bc}}$ & $6.23^{\mathrm{b}}$ & $7.89^{\mathrm{a}}$ & 0.02 & 0.012 \\
\hline
\end{tabular}

Six replicate pens per treatment, two pigs per pen.

${ }^{a-c}$ Means in the same row with different superscripts differ $(p<0.05)$.

$\mathrm{T} 1$, set temperature $\left(18^{\circ} \mathrm{C}\right) /$ actual temperature $\left(17.8 \pm 0.4^{\circ} \mathrm{C}\right)$; $\mathrm{T} 2$, set temperature $\left(22^{\circ} \mathrm{C}\right)$ /actual temperature $\left(21.7 \pm 0.3^{\circ} \mathrm{C}\right) ; \mathrm{T} 3$, set temperature $\left(26^{\circ} \mathrm{C}\right) /$ actual temperature $\left(25.9 \pm 0.2^{\circ} \mathrm{C}\right)$;

$\mathrm{T} 4$, set temperature $\left(30^{\circ} \mathrm{C}\right) /$ actual temperature $\left(29.6 \pm 0.3^{\circ} \mathrm{C}\right)$. 
temperatures resulted in reduced feed intake time. This was consistent with previous research reporting that high temperatures reduced feed intake $[7,8]$. This behavior seems to reduce the amount of heat generated by voluntarily limiting feed intake to reduce the metabolic heat generated by the pigs during digestion. In addition, as the temperature increased, the standing time decreased, the lying time increased, and the biting frequency increased. This was because, as Olczak et al. [9] reported, when the environment is poor, pigs prefer to rest. If the temperature is too high, pigs try to move to a cool place to lie down without contacting other pigs. However, if pigs cannot move, this makes the pig irritable and increases aggression. In the case of wallowing, there were positive correlations between the intensity of wallowing and temperature [10]. Wallowing in the mud is very effective and can decrease body temperature by $2^{\circ} \mathrm{C}$ [11]. Also, Huynh et al. [10] reported that as the temperature rose by one degree, the pig's wallowing increased by $1.2 \%$. This was because heat exchange within the environment depends upon skin contact from rubbing against mud. However, in pig house puddle is limited so pigs start lying down and wallowing in their own fecal [12-14]. In the case of drinking frequency, it seems that the drinking frequency of pigs is relatively increased as the amount of water required for the body, such as to control body temperature, moisture evaporating from the body, and the maintenance of blood homeostasis at high temperatures, increases.

The effects of humidity on pig behavior changes of experiment 2 are shown in Table 2 . The frequency of rooting and wallowing increased $(p<0.05)$ with increasing humidity. LH showed the lowest $(p<0.05)$ rooting frequency and $\mathrm{HH}$ showed the highest $(p<0.05)$ rooting frequency. Other behaviors were not affected $(p>0.05)$ by humidity changes. Similar to this experiment, Olczak et al. [9] reported that rooting increased at $\mathrm{HH}$. In the case of wallowing, positive correlations between humidity and wallowing were reported in a previous study [10]. Huynh et al. [10] reported that as the humidity increased, the pigs began to wallow at lower temperatures. It seems that as the humidity increases, also the moisture in the sawdust increases so $\mathrm{HH}$ cause the number of wallowing increases.

The effects of VOCs on pig behavior changes of experiment 3 are shown in Table 3. In this experiment, the VOCs concentrations did not $(p>0.05)$ change pig behavior. There is relatively little information about pigs' reactions to airborne pollutants [15]. The pig's response to the

Table 2. Effects of humidity on pig behavior

\begin{tabular}{|c|c|c|c|c|c|}
\hline & LH & MH & $\mathrm{HH}$ & SE & $p$-value \\
\hline \multicolumn{6}{|l|}{ Basic behavior (min/hour) } \\
\hline Feed intake & 5.31 & 5.19 & 5.48 & 0.04 & 0.871 \\
\hline Standing & 7.58 & 7.41 & 7.62 & 0.03 & 0.498 \\
\hline Lying & 43.66 & 44.02 & 43.89 & 0.07 & 0.685 \\
\hline Sitting & 2.97 & 3.01 & 2.84 & 0.01 & 0.205 \\
\hline \multicolumn{6}{|l|}{ Singularity behavior (count/hour) } \\
\hline Drink water & 4.76 & 4.92 & 4.88 & 0.03 & 0.681 \\
\hline Rooting & $1.21^{\mathrm{c}}$ & $1.77^{\mathrm{b}}$ & $2.43^{\mathrm{a}}$ & 0.02 & 0.047 \\
\hline Posture transition (lying-standing) & 3.71 & 3.80 & 3.61 & 0.01 & 0.312 \\
\hline Posture transition (standing-lying) & 3.55 & 3.76 & 3.56 & 0.02 & 0.195 \\
\hline Wallowing & $6.12^{\mathrm{c}}$ & $8.41^{\mathrm{b}}$ & $9.84^{\mathrm{a}}$ & 0.03 & 0.040 \\
\hline Biting & 0.15 & 0.17 & 0.16 & 0.01 & 0.787 \\
\hline
\end{tabular}

Six replicate pens per treatment, two pigs per pen.

${ }^{a-c}$ Means in the same row with different superscripts differ $(p<0.05)$.

LH, low humidity, set relative humidity (45\%)/actual relative humidity (44.8 $\pm 0.3 \%)$; $\mathrm{MH}$, middle humidity, set relative humidity $(60 \%) / a c t u a l$ relative humidity $(60.8 \pm 0.2 \%) ; \mathrm{HH}$, high humidity, set relative humidity $(75 \%)$ /actual relative humidity $(74.9 \pm 0.3 \%)$. 
Table 3. Effects of VOCs on pig behavior

\begin{tabular}{lrrrrrrrrr}
\hline & Day 1 & Day 2 & Day 3 & Day 4 & Day 5 & Day 6 & Day 7 & SE & $\boldsymbol{p}$-value \\
\hline Basic behavior (min/hour) & & & & & & & & \\
$\quad$ Feed intake & 4.87 & 4.89 & 4.81 & 4.77 & 4.73 & 4.72 & 4.69 & 0.11 & 0.380 \\
$\quad$ Standing & 6.32 & 6.18 & 6.44 & 6.68 & 6.34 & 6.81 & 6.72 & 0.08 & 0.813 \\
$\quad$ Lying & 44.97 & 45.12 & 44.78 & 44.93 & 45.03 & 45.10 & 44.81 & 0.23 & 0.569 \\
$\quad$ Sitting & 3.84 & 3.81 & 3.97 & 3.62 & 3.90 & 3.37 & 3.78 & 0.06 & 0.411 \\
Singularity behavior (count/hour) & & & & & & & & & \\
$\quad$ Drink water & 5.12 & 5.51 & 5.36 & 5.20 & 5.39 & 5.17 & 5.17 & 0.08 & 0.139 \\
Rooting & 1.08 & 1.11 & 1.16 & 1.07 & 1.15 & 1.03 & 1.02 & 0.02 & 0.233 \\
$\quad$ Posture transition (lying-standing) & 3.42 & 3.55 & 3.48 & 3.61 & 3.68 & 3.77 & 3.85 & 0.04 & 0.704 \\
$\quad$ Posture transition (standing-lying) & 3.39 & 3.56 & 3.49 & 3.58 & 3.66 & 3.81 & 3.89 & 0.11 & 0.685 \\
$\quad$ Wallowing & 6.34 & 6.75 & 6.38 & 6.41 & 6.98 & 7.01 & 7.24 & 0.09 & 0.091 \\
Biting & 0.18 & 0.15 & 0.14 & 0.17 & 0.20 & 0.21 & 0.18 & 0.02 & 0.198 \\
\hline
\end{tabular}

Six replicate pens per treatment, two pigs per pen.

VOCs, volatile organic compounds; Day 1, VOCs (39.4 \pm 1.5 ppb); Day 2, VOCs (60.2 \pm 1.4 ppb); Day 3, VOCs (130.4 \pm 2.1 ppb); Day 4, VOCs (146.9 \pm 4.0 ppb); Day 5, VOCs (272.5 $\pm 17.4 \mathrm{ppb})$; Day 6, VOCs $(480.5 \pm 21.8 \mathrm{ppb})$; Day 7 , VOCs $(738.9 \pm 29.3 \mathrm{ppb})$.

environment is complex and it is difficult to assess the importance and impact of individual pollutants in the environment [16]. In addition, it has been reported that harmful substances such as ammonia adversely affect the health of pigs. However, since the effect of VOCs on pig behavior has not been reported, further research is needed.

The effects of illuminance on pig behavior changes of experiment 4 are shown in Table 4. Lying time was the longest $(p<0.05)$ at $\mathrm{LI}$ and shortest at $\mathrm{HI}(p<0.05)$. Illuminance did not affect $(p$ $>0.05)$ pig behavior other than the lying time. This is consistent with the results of Taylor et al. [17]. In Taylor's [17] research pigs spent longest time in dimmest illuminance (2.4 lx) and spent least time in the brightest illuminance (400 lx) [17]. These results indicate that pigs show a strong preference for inactivity while in low-illuminated conditions. Thus, pigs take longer rest time in low-illuminated conditions. However, studies on the relationship between illuminance and pig behavior are extremely rare, and more research is needed.

Table 4. Effects of illuminance on pig behavior

\begin{tabular}{|c|c|c|c|c|c|}
\hline & LI & MI & $\mathrm{HI}$ & SE & $p$-value \\
\hline \multicolumn{6}{|l|}{ Basic behavior (min/hour) } \\
\hline Feed intake & 5.11 & 4.98 & 5.29 & 0.02 & 0.398 \\
\hline Lying & $46.85^{\mathrm{a}}$ & $45.10^{b}$ & $44.09^{c}$ & 0.03 & 0.010 \\
\hline Sitting & 3.35 & 3.41 & 3.40 & 0.01 & 0.846 \\
\hline Rooting & 0.98 & 1.11 & 1.09 & 0.01 & 0.681 \\
\hline Posture transition (lying-standing) & 3.98 & 3.74 & 3.95 & 0.03 & 0.446 \\
\hline Posture transition (standing-lying) & 3.90 & 3.71 & 3.91 & 0.01 & 0.786 \\
\hline Wallowing & 6.50 & 6.44 & 6.98 & 0.04 & 0.691 \\
\hline
\end{tabular}

Six replicate pens per treatment, two pigs per pen.

${ }^{\mathrm{a}-\mathrm{c} M e a n s}$ in the same row with different superscripts differ $(p<0.05)$.

$\mathrm{LI}$, low illuminance (470 lumens/45 Ix); MI, middle illuminance (1,055 lumens/103 Ix), HI, high illuminance (1,521 lumens/146 lx). 


\section{CONCLUSION}

Pig behavior is heavily influenced by the environment, especially temperature and humidity. More research is needed on the correlation between the environment and pig behavior for a highly efficient pig farming industry applying ICT.

\section{REFERENCES}

1. Lee JH, Lee DH, Yun W, Oh HJ, An JS, Kim YG, et al. Quantifiable and feasible estrus detection using the ultrasonic sensor array and digital infrared thermography. J Anim Sci Technol. 2019;61:163. https://doi.org/10.5187/jast.2019.61.3.163

2. Piñeiro C, Morales J, Rodríguez M, Aparicio M, Manzanilla EG, Koketsu Y. Big (pig) data and the internet of the swine things: a new paradigm in the industry. Anim Front. 2019;9:6-15. https://doi.org/10.1093/af/vfz002

3. Verdouw C, Tekinerdogan B, Beulens A, Wolfert S. Digital twins in smart farming. Agric Syst. 2021;189:103046. https://doi.org/10.1016/j.agsy.2020.103046

4. NRC [National Research Council]. Nutrient requirement of pigs. 11th ed. Washington, DC: The National Academies Press; 2012.

5. Yang KY, Jeon JH, Kwon KS, Choi HC, Ha JJ, Kim JB, et al. Classification of behavior at the signs of parturition of sows by image information analysis.J Korea Acad Ind Cooperation Soc. 2018;19:607-13. https://doi.org/10.5762/KAIS.2018.19.12.607

6. Korean Agency for Technology and Standards. KS A3011, KS recommended levels of illumination. Eumseong, Korea: Korean Agency for Technology and Standards; 1998.

7. Barnett JL, Hemsworth PH, Cronin GM, Jongman EC, Hutson GD. A review of the welfare issues for sows and piglets in relation to housing. Aust J Agric Res. 2001;52:1-28. https://doi. org/10.1071/AR00057

8. Silva BAN, Noblet J, Donzele JL, Oliveira RFM, Primot Y, Gourdine JL, et al. Effects of dietary protein level and amino acid supplementation on performance of mixed-parity lactating sows in a tropical humid climate. J Anim Sci. 2009;87:4003-12. https://doi.org/10.2527/ jas.2008-1176

9. Olczak K, Nowicki J, Klocek C. Pig behaviour in relation to weather conditions: a review. Ann Anim Sci. 2015;15:601-10. https://doi.org/10.1515/aoas-2015-0024

10. Huynh TTT, Aarnink AJA, Gerrits WJJ, Heetkamp MJH, Canh TT, Spoolder HAM, et al. Thermal behaviour of growing pigs in response to high temperature and humidity. Appl Anim Behav Sci. 2005;91:1-16. https://doi.org/10.1016/j.applanim.2004.10.020

11. Hörning B, Raskopf S, Simantke C, Boehnke E, Walter J, Schneider M. Argemäe schweinehaltung: grundlagen und beispiele aus der praxis [Species-suited pig husbandry: Principles and examples from practice]. Bad Dürkheim, Germany: Stiftung Okologie \& Landbau; 1999.

12. Hillmann E, Mayer C, Schön PC, Puppe B, Schrader L. Vocalisation of domestic pigs (Sus scrofa domestica) as an indicator for their adaptation towards ambient temperatures. Appl Anim Behav Sci. 2004;89:195-206. https://doi.org/10.1016/j.applanim.2004.06.008

13. Aarnink AJA, Schrama JW, Heetkamp MJW, Stefanowska J, Huynh TTT. Temperature and body weight affect fouling of pig pens. J Anim Sci. 2006;84:2224-31. https://doi.org/10.2527/ jas.2005-521

14. Spoolder HAM, Aarnink AJA, Vermeer HM, van Riel J, Edwards SA. Effect of increasing temperature on space requirements of group housed finishing pigs. Appl Anim Behav Sci. 2012;138:229-39. https://doi.org/10.1016/j.applanim.2012.02.010 
15. Kim KY, Ko HJ, Kim HT, Kim CN, Byeon SH. Association between pig activity and environmental factors in pig confinement buildings. Aust J Exp Agric. 2008;48:680-6. https://doi. org/10.1071/EA06110

16. Nicks B, Marlier D, Canart B. Air pollution levels in pig houses. In: Proceedings of the International Livestock Environment Symposium IV; 1993; Warwick, UK.

17. Taylor N, Prescott N, Perry G, Potter M, Le Sueur C, Wathes C. Preference of growing pigs for illuminance. Appl Anim Behav Sci. 2006;96:19-31. https://doi.org/10.1016/j.applanim.2005.04.016 